\title{
Impact of Environmental Tobacco Smoke on Pulmonary Functions of Females
}

\begin{abstract}
Sadaf Zia, Hamid Shafiq, Fauzia Jamshed, Rana Muhammad Tahir Salam
ABSTRACT

Background:Environmental tobacco smoke (ETS) or passive smoking has an emerging burden on the society thus affecting the quality of individual's life. According to World Health Organization ETS is referred to the involuntary inhalation of burning tobacco products emitted from the smoking devices. More than 4000 harmful compounds including carcinogens are emitted from burning cigarettes and cigars etc, which are extremely harmful for human health. Pakistan has high tobacco consumption. Due to this reason women and children are frequently exposed to indoor ETS. Subjects with exposure to ETS have same ill effects as light active smokers.

Aim: To evaluate the lung functions of passive smokers and to compare with non-smokers of the same age and social background.

Methods: The study was conducted in a private hospital of Faisalabad. 250 female subjects aged 15- 45 years were included in the study. Data was collected by specially designed structured proforma and lung Function tests were performed by spirometry. Data was analyzed by using SPSS 20 version. Pvalue $\leq 0.05$ was taken as significant.

Results: 250 females participated in study. $61.2 \%$ of total study population was exposed to tobacco smoking. Out of total 250 subjects, $155(62 \%)$ had undiagnosed airway obstruction. FEV1, FVC and FEV1/ FVC ratio were lower in passive smokers as compared to non- smokers. Significant difference was found in FEV1 $\left(0.003^{*}\right)$, FVC (P value $0.002 *)$, FEV1/FVC $(0.001 *)$. FEV1/FVC ratio of $<0.70$ was noted in $89.5 \%$ and $18.5 \%$ of total passive smokers and nonsmokers respectively (obstructive air way pattern). $55 \%$ of subjects with reduced lung function parameters also reported chronic cough and shortness of breath.
\end{abstract}

Conclusion: Airway obstruction was found among majority of passive smokers, confirmed by reduced lung function test.

Key Words: Environmental tobacco smoke, Spirometry, lung function parameters, passive smokers.

\section{Introduction}

Environmental tobacco smoke (ETS) or passive smoking is an emerging burden on the society, affecting the quality of individual's life. ${ }^{1}$ According to World Health Organization (WHO) ETS is referred to the involuntary inhalation of burning tobacco products emitted from the cigars, pipe, bidi, cigarettes, wave (shisha) and other smoking devices by nonsmokers in proximity of smokers. ${ }^{2}$ However the most common source is the cigarette, as tobacco is most widely used in this form worldwide. ${ }^{2}$ Passive smokers are not only exposed to tobacco exhaled by smokers (main stream smoke) but as well as from side stream smoke (smoke released from the end of a burning cigarette), which contain about $4 / 5$ of total smoke. ${ }^{2}$ More than 4000 compounds including carcinogens, are emitted from burning cigarettes and cigars etc.

\section{Dr. SadafZia}

Associate Professor

University medical and Dental College Faisalabad

Maj. Gen.(R)Prof.Dr. Hamid Shafiq HI(M)

Professor

Aziz Fatimah Medical and Dental College, Faisalabad.

Dr. Fauzia Jamshed

Postgraduate/MCPS Trainee

PNS Shifa Hospital Karachi

Dr.Rana Muhammad Tahir Salam, Sonologist

Aziz Fatimah Medical and Dental College, Faisalabad.

Correspondence:

Dr. SadafZia

E.mail:drsadafzia9@gmail.com
It contains nicotine, ammonia, benzopyrine and carbon monoxide (CO) which are extremely harmful for human health. ${ }^{2,3}$ It is estimated that two times more $\mathrm{CO}$ and nicotine and 15 times more formaldehyde are emitted from side stream smoke than main stream and these emission are appox. three times more toxic than the mainstream element of ETS. ${ }^{2}$ Increase emission of CO from burning tip of smoking devices impair the body's ability to efficiently diffuse and transport oxygen leading to tissue hypoxia, reduction in exercise tolerance and shortness of breath among the active smokers as well as passive smokers. ${ }^{5}$ All these factors along with nicotinic induced vasoconstriction causes precipitation of pulmonary and cardiovascular ailments. ${ }^{6,7}$ Some of the respiratory diseases include asthma, emphysema and lung cancers are depending upon effective dose of ETS over a time. ${ }^{8,9}$ Subjects with exposure to ETS have same ill effects as light active smokers (who smoke 10 cigarettes/day). ${ }^{6}$ Pakistan has high tobacco consumption because of high smoking rate of appox: $36 \%$ in Pakistani men and 6- 9\% in women. ${ }^{10,11}$ Smoking is considered an undesirable practice among Pakistani women due to cultural barriers in our society. Pakistani Women are considered to be minority in terms of active smoking but majority as passive smokers. Evidences are showing that half of the Pakistani ${ }^{12}$ and Chinese women 
are frequently exposed to indoor ETS and its exposure to pregnant women are the leading cause of preterm deliveries, low birth weight babies, sudden infant death syndrome, atopic asthma and ear infections in neonate. ${ }^{2,3,}$ ${ }^{13}$ Hospitalization of $35.4 \%$ children with respiratory ailments including pneumonia and reduced lung function are attributed to ETS or second hand smoking. ${ }^{14}$ Children are more vulnerable to respiratory problems due to smaller bronchial tree and less developed immune system. ${ }^{15}$ ETS is the constant threat to the health of females as wells children. It results in compromising the quality of life of future generation. ${ }^{15,16}$ Studies conducted in past have reported that involuntary inhalation of cigarette smoke increases $25-30 \%$ risk of getting cardiovascular diseases and $20-30 \%$ risk for lung cancer among passive smokers. ${ }^{17}$ Study conducted in china has documented that 1.9 million mortalities in Chinese population due to COPD are attributed to ETS. ${ }^{18} 6000$ premature deaths globally are attributed to ETS. ${ }^{17}$ ETS is a preventable risk factor for human health. It is imperative to highlight this hazardous risk factor and launch effective awareness programs for the general population. Such measures can prevent or decrease the load of diseases related to active as well as passive smoking. Safety of women and children who constitute the major part of population across the world need to be looked after. Females have an important role in the family in taking care of their spouse and children along with other family members. In developing countries, like ours, females are mostly neglected resulting delay in the diagnosis /management of their ailments. Lack of knowledge among the smokers frequently results in spreading of environmental tobacco smoke among family members friends and colleagues. This has direct impact on their physical as well mental health. ${ }^{15}$ Smokers should know their responsibilities and quit smoking to save themselves as well as their family members/peoples around them. This study was specially designed to evaluate lung function tests of the female passive smokers (who are frequently exposed to ETS) as compared to nonsmoker females of their age with similar socioeconomic background.

Methodology

The current cross sectional study comprised of 250 female subjects, age ranging from $15-45$ years. The study was conducted from September 2018 to November 2018 in a private hospital of Faisalabad. Subjects participated voluntarily. Ethical approval from the ethical committee was taken prior to commencement of the study. Volunteer subjects were female employees, visitors, or attendants of hospitalized patients.

\section{Inclusion criteria}

All self-reported volunteers with history of exposure to passive tobacco smoking through cigarette, bidi and cigar were included as the passive smokers. Subjects who had no significant exposure to tobacco smoking were taken as nonsmokers. All the included participants were not previously screened for COPD and had no previous history of any treatment for airway obstruction Exclusion criteria

Active smokers, exposures to factory smoke, male passive smokers, subjects who were unable to perform procedure due to oral lesions or with spine and thoracic cage deformities (kyphosis, scoliosis and fused ribs,) were excluded. Subjects who had previous diagnosis of respiratory diseases including, asthma/COPD, restrictive lung disease, tuberculosis and lung cancers. Subjects with history of systemic diseases affecting the respiratory system were also excluded. Individuals with existing or previous therapies for airway obstruction such as bronchodilators and steroids and with morbid obesity with BMI $\geq 40 \mathrm{~kg} / \mathrm{m}^{2}$ were excluded. (In order to avoid confounders and limit bias). Proper history taking and clinical examination of all the subjects were done as per specially designed structured proforma. More stress was laid on the personal history (addictions), residential area, occupational history, family history etc. to find the source of passive smoking. Question concerning symptom related to COPD such as cough with sputim and breathlessness were also inquired. Confidentiality and anonymity of the each participant was assured. After taking informed consent and explaining the procedure, each participant was subjected to spirometry test, using calibrated compact spirometer. Forced expiratory volume in $1^{\text {st }}$ second (FEV1), force vital capacity (FVC) and FEV1/FVC ratio were determined according to guidelines by European respiratory society (ERS) and American Thoracic Society (ATS).$^{19}$ After correcting volume and zeroing spirometry pod, spirometry were performed by seating subject in upright position and using a nose clip to avoid air leakage through nose. Volunteers were asked to take tidal breathing for 1 minute followed by inhaling as deeply as possible and then exhaling as deeply as possible through a noncompressible mouthpiece for at least 6 seconds (99\% of the air bursts out forcefully in the first six seconds). Three acceptable measures were taken to minimize the errors. Highest reading was saved for data as per ATS and ERS guidelines ${ }^{20}$ GOLD criteria was used to assess lung function test. FEV1 $80 \%$ was taken as normal, FEV1 < $80 \%$ as stage 1 , FEV1 between $79-50 \%$ as stage II and $30-40 \%$ as stage III and $\leq 30 \%$ was taken as stage IV 
COPD. FEV1/FVC $<70 \%$ were considered as $\mathrm{COPD}^{21}$ FEV1/FVC is reported as a decimal fraction. It helps to minimize the miscommunication as recommended by American Thoracic Society. ${ }^{3,19}$

\section{Statistical analysis}

Data was analyzed by using SPSS 20 version. Data is expressed as mean and standard deviation for continuous variables (age height weight BMI, lung function parameters).Categorical variables are presented as frequency (n) and percentage (\%) . $\mathrm{X}^{2}$ test was used to compare percentages. Independent t- test was applied to compare the means of spirometric parameters (FEV1, FVC, FEV1/FVC) between study groups. P value $\leq 0.05$ was taken as significant.

\section{Results}

This study comprised of 250 subjects including passive smokers and nonsmokers. The basic characteristics of all subjects are presented in Table-1. Figure 1 is indicating distribution of study population. It reveals that 153(61.2 $\%)$ of total study population was exposed to ETS. Table 2 is showing that out of total 250 subjects, 155 (62\%) were found to have air way obstruction. It further indicates that $89.5 \%$ and $18.5 \%$ of total passive smokers and nonsmokers respectively had undiagnosed airflow obstruction determined by FEV1/FVC ratio of $<0.70$. Difference was statistically significant with $\mathrm{P}$ value $0.0001 *$ (Table2). $55 \%$ of subjects with reduced lung function parameters were also reported chronic cough and shortness of breath but they never screened for COPD prior to this study. Mean FEV1, FVC and FEV1/FVC ratio were lower in passive smokers as compared to non-smokers. All three spirometric parameters were lower in passive smokers as compared to nonsmokers but greater reduction was noted in FEV1 $\left(\mathrm{P}\right.$ values $\left.0.003^{*}\right)$ and $\mathrm{FEV} 1 / \mathrm{FVC}\left(\mathrm{P}\right.$ value $\left.0.001^{*}\right)$ values as compared to FVC (P value $0.002 *$ ) (Figure 2).

Table 1: Descriptive of study population

\begin{tabular}{|l|c|c|}
\hline \multicolumn{1}{|c|}{ Study Variables } & Mean & Std. Deviation \\
\hline Age $($ years $)$ & 22.57 & 3.94 \\
\hline Height $(\mathrm{cm})$ & 156.50 & 6.11 \\
\hline Weight $(\mathrm{g})$ & 57.4 & 11.50 \\
\hline BMI $\left(\mathrm{kg} / \mathrm{m}^{2)}\right.$ & 23.70 & 3.12 \\
\hline FEV $1(\mathrm{~L} / \mathrm{s})$ & 3.15 & 1.16 \\
\hline FVC $(\mathrm{L} / \mathrm{s})$ & 3.55 & 0.63 \\
\hline FEV $1 / \mathrm{FVC}$ & 1.89 & 0.31 \\
\hline
\end{tabular}

BMI: Body mass index, cm: centimeters, kg: kilograms, m: meters $\mathrm{L} / \mathrm{s}$ liters/seconds, FEV1: force expiratory volume in $1^{\text {st }}$ second, FVC: force vital capacity
Figure1: Distribution of Passive Smokers and Non Smokers among Study Population. $(\mathrm{N}=\mathbf{2 5 0})$

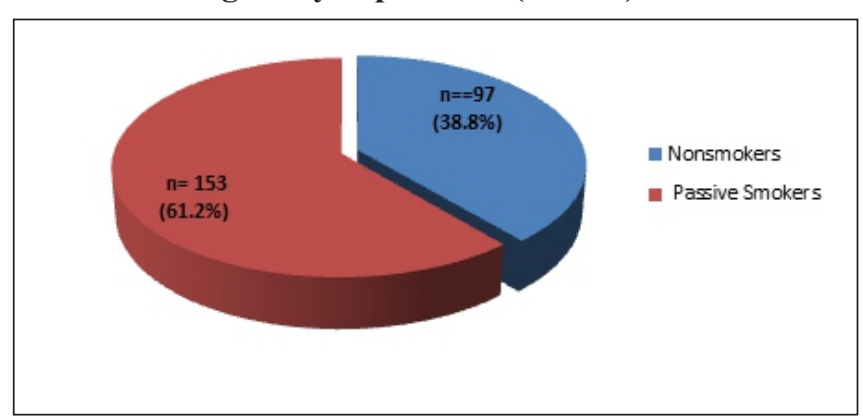

Table 2: Air Flow Obstruction among the Study Population Determined by $\mathrm{FEV}_{1} / \mathrm{FVC}$ ratio of $<0.70$

\begin{tabular}{|c|c|c|c|}
\hline \multirow{2}{*}{ Study Subjects } & \multicolumn{2}{|c|}{$\begin{array}{c}\text { Air flow obstruction } \\
\text { FEV } 1 \text { FVC ratio of }<\mathbf{0 . 7 0}\end{array}$} & \\
\cline { 2 - 4 } & $\begin{array}{c}\text { YES } \\
\text { N (\%) }\end{array}$ & $\begin{array}{c}\text { NO } \\
\text { N }(\%)\end{array}$ & Total \\
\hline Passive Smokers & $137(89.5)$ & $16(10.5)$ & 153 \\
\hline Nonsmokers & $18(18.5)$ & $79(81.5)$ & 97 \\
\hline Total & $155(62)$ & $95(38)$ & 250 \\
\hline P Value & \multicolumn{2}{|c|}{$0.0001 *$} \\
\hline P value is obtained by $X^{2}$ test. $=0.05$ is considered as significant. \\
\hline
\end{tabular}

FEV1/FVC ratio of $<0.70$ is GOLD criteria for diagnosis of COPD

Figure 2: Comparison of Lung Function Test among Study Population. $(\mathrm{N}=\mathbf{2 5 0})$

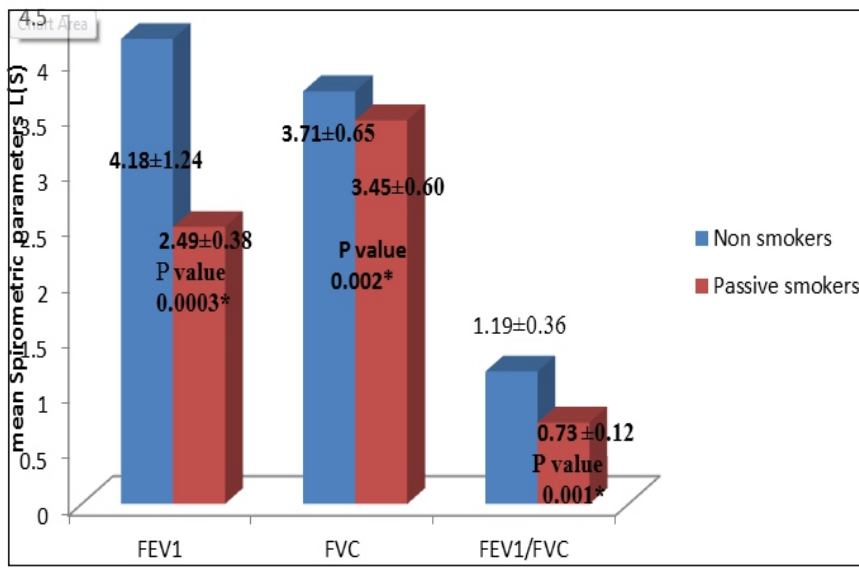

FEV1: force expiratory volume in $1^{\text {st }}$ second, FVC: force vital capacity Comparison of mean by t- test

$P$ value $\leq 0.05$ is considered as significant

\section{Discussion}

Majority of Pakistani population comprises of females and children, who are more vulnerable to morbidities and injuries associated with environments. ${ }^{22}$ These innocent lives are continuously suffering from the environmental 
pollution for which they are not responsible. According to Global Adult Tobacco Survey (GATS) 2014, 86\% of the Pakistani population has exposure to ETS. $45-50 \%$ exposure is indoor at homes, $76-86 \%$ is in a restaurant and on public transportation. ${ }^{12}$ Major part of the pollution is attributed to environmental tobacco smoke spreading from the male smoker population which has impact on physical as well as mental health of the peoples around them. ${ }^{15}$ Females and children whose family members are smokers, are at risk of getting pulmonary as well as extra pulmonary morbidities. It is estimated by the previous researches that the children of smokers have higher rates of respiratory problems like asthma, pneumonia and lower and upper respiratory tract infections, lung cancers and frequent hospitalization than children of nonsmokers. ${ }^{23}$ Many studies in the past were conducted to highlight the health issues of the children but relatively very few documentation on female passive smokers who have the major contribution in taking care of their families are available. Female are mostly ignored in our society and less importance is given to their health. It was found that half of the pregnant women who are exposed to indoor involuntary smoking, results not only in the reduction of their lung functions but also of their babies, thus compromising the quality of lives of future generation too. ${ }^{24}$ Very few studies were performed in the past to evaluate the lung function of females. Aim of this study was to evaluate the lung functions of healthy female passive smokers by spirometry and compare it to nonsmoker females of the same age group and social background. $61.2 \%$ of the total current study population was exposed to ETS, this figure corroborates the results documented by Zubair T who reported $63.84 \%$ of same exposure in his studied population at Karachi. ${ }^{1}$ Bird Y, etal study also reported $50 \%$ of exposure to ETS in their studied Mexican population. ${ }^{25}$ Our study found significant reduction in FEV1, FVC and FEV1/FVC in female passive smokers as compared to the nonsmoker females. Current study found that the $62 \%$ of the total studied population had undiagnosed airway obstruction with lung function parameters less than $70 \% .89 .5 \%$ and $18.6 \%$ of total passive smokers and nonsmokers respectively have air way obstruction with a statistically significant difference ( $P$ value $0.0001 *$ ). 55\% of subjects with reduced lung function also reported presence of symptoms like cough and breathlessness. This study is in agreement with the study conducted by zubair $\mathrm{T}$ and his colleagues at one of the renowned public sector hospital at Karachi who reported decline in lung function parameters in passive smokers and $12.24 \%$ of exposed population had undiagnosed COPD. ${ }^{1}$ Although we found reduction in all three studied parameters but greater decline was found in FEV1 and FEV1/FVC in contrast to FVC. These results are also supported by many other researches conducted in Pakistan as well as other regions across the world in the past. ${ }^{20,25,26,27}$ Health promotion and prevention is the most neglected part of our society. Health awareness and motivational programs should be arranged by public and private health professionals concerning this issue. Smokers should be motivated to cease smoking and lessen the ETS for provision of safer environment for our nation building blocks and to save innocent lives.

\section{Conclusion}

Majority of the studied population had exposure to tobacco smoke (ETS). Undiagnosed air way obstruction was found in passive smokers. FEV1,FVC, and FEV1/FVC ratio, are lower in passive smokers than nonsmokers, which is indicative of deterioration of lung function. This study proved beyond doubt that passive smoking has negative effect on lung functions.

Strength and limitation

The strength of the study was its standardized protocol like the questionnaire and gold standard test spirometry for assessment of lung functions. This study would be more scientific if we could have the opportunity of clinical assessments of symptoms and post bronchodilator spirometry for the subjects with lower lung function parameters. (Diagnostic criteria for COPD by GOLD). Due to a cross-sectional nature of the study, we cannot infer the association between passive smoking and decline in lung functions, further studies with longitudinal nature are needed.

The study population was recruited from only one hospital which may not represent whole female population of Pakistan.

Recommendation

Implementation for assuring legislation to ban smoking at public places and transports to provide $100 \%$ smoke free environment from government side, as recommended by WHO framework Convention on Tobacco Control (FCTC).

$\begin{array}{ll}\text { Conflict of interest: } & \text { None } \\ \text { Funding Source: } & \text { None }\end{array}$ 


\section{References}

1. Zubair T, Abbasi A, Khan OA, Amer E. Role of passive smoking in non-smoking related chronic obstructive pulmonary disease J Pak Med Assoc.2018;68(9):13101315.

2. Öberg M, Jaakkola MS, Prüss-Üstün A, Schweizer C, Woodward A. Second-hand smoke: Assessing the environmental burden of disease at national and local levels. Geneva, World Health Organization, 2010 (WHO Environmental Burden of Disease Series, No. 18).

3. Global Initiative for Chronic Obstructive Lung Disease (GOLD). Global strategy for the diagnosis, management, and Prevention of chronic obstructive lung diseases (GOLD). 2018report. https://goldcopd.org/wpontent/uploads/2017/11/GOLD-2018-v6.0-finalrevised-20-Nov_WMS.pdf.

4. Öberg M, Jaakkola MS, Woodward A, Peruga A, Prüss-Ustün A.Worldwide burden of disease from exposure to second-handsmoke: a retrospective analysis of data from 192 countries. Lancet.2011;377:139-46.

5. Whiteford L. Nicotine, $\mathrm{CO}$ and $\mathrm{HCN}$ : the detrimental effects of smoking on wound healing. Br J Community Nurs. 2003;8(12):22-26.

6. Kobayashi Y, Takeuchi T, Hosoi T, et al. Effects of habitual smoking on cardiorespiratory responses to submaximal exercise. J Physiol Anthropol Appl Human Sci. 2004;23(5):163-169.

7. Fischer F, Kraemer A. Meta-analysis of the association between second-hand smoke exposure and ischaemic heart diseases, COPD and stroke. BMC Public Health. 2015;15:1202.

8. Ambrose JA, Barua RS. The pathophysiology of cigarette smoking and cardiovascular disease: an update. J Am Coll Cardiol. 2004;43(10):1731-1737.

9. Habibullah S, Soomro IB. Effect of smoking on the health of family members in District South Karachi. Pak J Med Res. 2009; 48:44-7.
10.Mal R, Rizvi N, Rathi S. Prevalence of Smokers among Air-Conditioned Coaches, Pakistan. J Pak Med Assoc. 2001; 51:405-6.

11. Iqbal N, Irfan M, Ashraf N, Awan S, Khan JA. Prevalence of tobacco use among women: a cross sectional survey from a squatter settlement of Karachi, Pakistan. BMC research notes. 2015 Dec;8(1):469.

12. Ahmed R, Rizwan-ur-Rashid MP, Ahmed SW. Prevalence of cigarette smoking among young adults in Pakistan. J Pak Med Assoc. 2008 Nov;58(11):597-601.

13. Saqib MAN, Rafique I, Qureshi H, Munir MA, Bashir $\mathrm{R}$, Arif BW, et al.Burden of Tobacco in Pakistan Findings from Global Adult Tobacco Survey 2014. Nicotine Tob Res. 2017.

14. Ahn A, Edwards KM, Grijalva CG, Self WH, Zhu Y, Chappell JD, Arnold SR, McCullers JA, Ampofo K, Pavia AT, Bramley AM. Secondhand smoke exposure and illness severity among children hospitalized with pneumonia. The Journal of pediatrics. 2015; 167(4):86974.

15. Cinar N, Dede C, Cevahir R, Sevimli D. Smoking status in parents of children hospitalized with a diagnosis of respiratory system disorders. Bosnian journal of basic medical sciences. 2010; 10(4):319-22.

16. Baheiraei A, Ghafoori F, Nedjat S, Foroushani AR. Socio-demographic characteristics and secondhand smoke exposure among women. Tanaffos. 2013;12(2):41-47.

17. Bird Y, Staines-Orozco H, Moraros J. Adolescents' smoking experiences, family structure, parental smoking and socio-economic status in Ciudad Juárez, Mexico. Int J Equity Health. 2016;15(1):29.

18. Yin $\mathrm{P}$, Jiang CQ, Cheng KK, Lam TH, Lam KH, Miller MR, et al.Passive smoking exposure and risk of COPD among adults in China: the Guangzhou Biobank Cohort Study. Lancet. 2007; 370:751-7.

19. Rakesh PS, Lalu JS, Leelamoni K. Prevalence of exposure to secondhand smoke among higher secondary school students in Ernakulam District, Kerala, Southern 
India. Journal of pharmacy \& bioallied sciences. 2017; 9(1):44.

20. Bruce H. Culver, Brian L. Graham, Allan L. Coates, Jack Wanger etal Recommendations for a Standardized Pulmonary Function Report An Official American Thoracic Society Technical Statement. Am J Respir Crit Care Med. 2017; 196(11): 1463-1472.

21. Jawed S, Ejaz S, Rehman R. Influence of smoking on lung functions in young adults. J Pak Med Assoc. 2012;62(8):772-775.

22. Global Initiative for Chronic Obstructive Lung Disease. Pocket guide to COPD Diagnosis Management and Prevention. Amazon: Global Initiative for Chronic Obstructive Lung Disease; 2016.

23. Qureshi FM, Khalid N, Nigah-e-Mumtaz S, Assad T, Noreen K. First aid facilities in the school settings: Are schools able to manage adequately?. Pakistan journal of medical sciences. 2018; 34(2):272-76.

24. Hammad M, Atta K, Manzoor M, Tariq M, Saeed Z, Masood Z, et al.Association of passive smoking with respiratory symptoms and clinical correlates, among married women, in a rural community in Islamabad. J Pak Med Assoc. 2010; 60:601-4.
25. Hofhuis W, de Jongste JC, Merkus PJ. Adverse health effects ofprenatal and postnatal tobacco smoke exposure on children. Arch Dis Child. 2003; 88: 1086-90.

26. Bird Y, Staines-Orozco H. Pulmonary effects of active smoking and secondhand smoke exposure among adolescent students in Juárez, Mexico. International journal of chronic obstructive pulmonary disease. 2016; 11: 1459-67.

27. Gibbs K, Collaco JM, McGrath-Morrow SA. Impact of tobacco smoke and nicotine exposure on lung development. Chest. 2016; 149(2):552-61.

28. Merghani TH, Saeed AM. The relationship between regular second-hand smoke exposure at home and indicator of lung function in healthy school boys in Khartoum. Tobacco control. 2013; 22(5):315-8.

29. WHO. Report to Parties on Framework Convention on Tobacco Control. Second Session. First Report of Committee A. Geneva, Switzerland: WHO; 2007. Available from:

http://www.apps.who.int/gb/fctc/E/E_it2.htm. [Last accessed on 2016 Aug 22].

\section{Author`s Contribution}

Dr. Sadaf Zia:

Study design, data collection, manuscript writing, revised and approved the manuscript.

Maj. Gen. (R) Prof. Dr. Hamid Shafiq HI(M):

Study design, supervise throughout the research, manuscript writing, revised all the intellectual and scientific contents and approved the manuscript.

Dr. Fauzia Jamshed:

Study design, data analysis, result interpretation, write up of manuscript, editing and formulation of tables, revised and approved the manuscript.

Dr. Rana Muhammad Tahir Salam:

data collection, manuscript writing, revised and approved the manuscript. 